\title{
Commentary: Quality improvement project-A model for excellence
}

\author{
Antonio Miceli, $\mathrm{MD}, \mathrm{PhD}$
}

From the Minimally Invasive Cardiac Surgery Department, Istituto Clinico Sant'Ambrogio, Milan, Italy.

Disclosures: Author has nothing to disclose with regard to commercial support.

Received for publication May 25, 2019; accepted for publication May 28, 2019; available ahead of print July 11 , 2019

Address for reprints: Antonio Miceli, MD, PhD, Minimally Invasive Cardiac Surgery Department, Istituto Clinico Sant'Ambrogio, Via Faravelli 16, Milano, Italy (E-mail: Antoniomiceli79@alice.it).

J Thorac Cardiovasc Surg 2020;159:1796-7

$0022-5223 / \$ 36.00$

Copyright (C) 2019 by The American Association for Thoracic Surgery

https://doi.org/10.1016/j.jtcvs.2019.05.071

Assessment of patient care started in 1800, when Florence Nightingale was troubled by her observation that hospitalized patients died at higher rate than those treated out of the hospital. Her intuition was to understand that raw mortality was not accurate in reflecting the "real" outcome, because it did not account for patient's morbidities. This was the beginning of risk stratification, defined nowadays as the ability to predict outcomes accounting for differences in patient risk factors so that patient outcomes can be used as an indicator of quality of care. ${ }^{1}$

Quality of care is of central importance in the monitoring the health system, and the most important outcome for quality is mortality. Database, outcome-adjusted analysis, morbidity and mortality conferences, and adoption of guidelines have brought excellent results, but to maintain these levels a continuous monitoring system, which allows health care systems to identify and solve problems through quality improvement initiatives, is mandatory. ${ }^{2}$ In this issue of the Journal, Worrall and colleagues ${ }^{3}$ reported a significant $50 \%$ reduction in observed to expected mortality (and morbidity) ratio for patients undergoing isolated coronary artery bypass grafting after adoption of a multifaced quality improvement (QI) initiative at 14 cardiac institutions within the Providence Health and Services organization. During a 2.5-year intervention period, mortality and observed to expected mortality ratio dropped from $2.5 \%$ and 1.9 to $1.2 \%$ and 0.59 , respectively, without a change in expected mortality or case volume. Many factors have contributed to these outstanding results. The keys of success for the development of QI process have been the regular sharing of unblinded data, teleconferences and in-person meetings for an annual observed to expected mortality target, and standardization of cardiac care process with implementation of perioperative checklists. Most important were the identification of underperforming institutions and creation of nonpunitive QI action plans.

In this regard, 6 of 14 cardiac centers were recognized as underperforming. After QI intervention, 4 centers improved, 1 was brought under mentorship by a high-

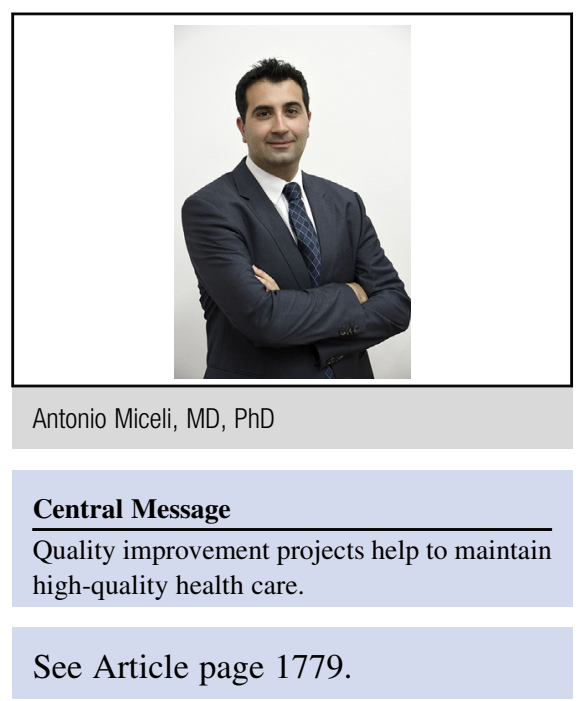

performing program, and 1 was closed and consolidated into a neighboring program. Interestingly, the closed program accounted for only $5 \%$ of the total volume of centers analyzed. Furthermore, there were some centers that performed fewer than 30 cases per year. This raises the problem of low surgical volume as a predictor of hospital performance. Recently, it has been shown that there is a clear relationship between hospital coronary artery bypass grafting volume and mortality in Europe, implying a "safe" threshold volume of 415 cases per year. ${ }^{4}$ This analysis was performed on patients undergoing coronary artery bypass grafting from 2007 to 2009 , however, and did not account for technical improvements in the last decade. Nevertheless, Kurlansky and coworkers ${ }^{5}$ demonstrated that surgical outcomes are not associated with program or surgeon volume but are directly correlated with the focus on quality, as manifested by compliance with evidence-based quality standards. Learning curve is another factor that may affect surgical outcome. ${ }^{6}$ In this regard, Worrall and colleagues $^{3}$ did not investigate the effect of learning curve of young surgeon. A cumulative sum (CUSUM) analysis would have been useful in monitoring performance and alerting a surgeon to suboptimal performance.

Finally, results may have been affected by the study periods. Patients' risk profiles were different among baseline, intermediate, and outcome periods. Even though outcomes were adjusted for Society of Thoracic Surgeons risk profile, recalibration of the risk score was not performed. 
This study highlights the important of monitoring surgical outcomes at institutional, regional, and national levels, with the aim of applying QI projects to maintain highquality health care and model the excellence.

\section{References}

1. Cohen IB. Florence Nightingale. Sci Am. 1984;250:128.

2. Ferraris VA, Edwards FH, Shahian DM, Feraris SP. Risk stratification and comorbidity. In: Cohn LH, ed. Cardiac surgery in the adult. 3rd ed. New York: McGrawHill; 2008:199-245.
3. Worrall N, Brevig J, Jin R, Gluckman T, Hunter R, Ducsik M, et al. Reduction in coronary artery bypass grafting surgery mortality and morbidity during a 3-year multicenter quality improvement project. J Thorac Cardiovasc Surg. 2020;159: 1779-91.

4. Gutacker N, Bloor K, Cookson R, Pale CP, Maynard A, Pagano D, et al. Hospital surgical volumes and mortality after coronary artery bypass grafting: using international comparisons to determine a safe threshold. Health Serv Res. 2017; 52:863-78.

5. Kurlansky PA, Argenziano M, Dunton R, Lancey R, Nast E, Stewart A, et al. Quality not volume, determines outcome of coronary artery bypass surgery in a universitybased community hospital network. J Thorac Cardiovasc Surg. 2012;143:287-93.

6. Williams SM, Parry BR, Schlup MM. Quality control: an application of the cusum. BMJ. 1992;304:1359-61. 